\title{
Editorial (ERPP Issue 8.1)
}

\author{
Oon-Seng Tan
}

Published online: 10 February 2009

(C) Springer Science+Business Media B.V. 2009

Welcome to the first issue of ERPP for the year 2009. An exciting event at the end of 2008 was the successful organisation of the Asia-Pacific Educational Research Association (APERA) conference from 26th to 28th of November. The theme of the conference, Educational Research for Innovation and Quality in Education: Policy \& Pedagogical Engagements across Contexts, reflects APERA's commitment to facilitate research that can bring quality and innovation into educational policies and practices. APERA, National Institute of Education, Singapore (NIE) and Educational Research Association of Singapore (ERAS) jointly hosted this conference at the NIE campus. The APERA 2008 conference brought together over 1,000 participants from 39 countries across the globe to discuss the innovative ways of facilitating teaching and learning that would ultimately benefit the learners in the classroom. A detailed conference report by $\mathrm{Ng}$ is found in this issue. The ERPP will also provide a platform for selected high quality papers from the conference to be published.

In this issue, we continue to explore a wide range of educational issues from South Korea, Philippines, Australia and Singapore. Brown's paper analyses the perceptions of student misconduct, perceived respect for teachers and support for corporal punishment among school teachers in South Korea. A quantitative research approach was used to analyse the data gathered from a survey of 110 middle and high school teachers in South Korea. The results of the study and its implications on policy initiatives in South Korean schools were discussed.

The article by Guzman and Fabian traces the live experience of Information and Communications Technology (ICT) of adolescents in the Philippines. The use of qualitative inquiry surfaced three distinct but connected conceptual zones of ICT, namely the Zone of Technology Perspective (ZTP), Zone of Technology Power and Efficacy (ZTPE) and Zone of Technology Deficits (ZTD). The paper also discusses the implications of these findings on educational policies that can enhance the learning experiences and developments of Filipino adolescents.

O.-S. Tan $(\bowtie)$

National Institute of Education, Nanyang Technological University, Nanyang Avenue,

Singapore, Singapore

e-mail: oonseng.tan@nie.edu.sg 
Jones' article explores the National Framework for Values Education in Australia. Through a Critical Discourse Analysis approach, the article identifies dominant discourses inherent in the framework and argues for alternative practices and policies, that are more student-centred, and that can cater to a diverse student population.

The article by Chong and Low investigates the formation of teacher identity among trainee teachers from pre-service training to the end of the first year of teaching. The paper identifies the factors influencing the emerging sense of teacher's professional identity and discusses the implications of the research findings in the context of teacher-education and teacher-development.

We hope that the articles in issue 8.1 will generate further discussions and collaborations among educators and researchers so that good educational philosophies and practices may be shared globally. We look forward to your valuable contributions to the ERPP.

Oon-Seng Tan

Editor-in-chief 